\title{
Biomass accumulation in a biofilter treating toluene at high loads. Part 1:Experimental performance from inoculation to clogging
}

\author{
Antonio D. Dorado $^{\mathrm{a} *}$, Juan A. Baeza ${ }^{\mathrm{b}}$, Javier Lafuente ${ }^{\mathrm{b}}$, David Gabriel ${ }^{\mathrm{b}}$ and Xavier \\ Gamisans $^{\mathrm{a}}$ \\ ${ }^{a}$ Department of Mining Engineering and Natural Resources, Universitat Politècnica de Catalunya, Bases de \\ Manresa 61-73, 08240 Manresa, Spain \\ ${ }^{b}$ Department of Chemical Engineering, Universitat Autònoma de Barcelona, Edifici C, 08193 Bellaterra, \\ Barcelona, Spain

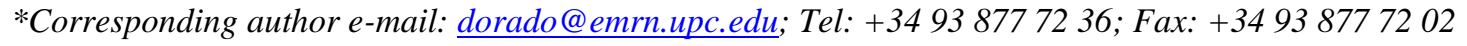

\begin{abstract}
Biomass accumulation was studied in a biofilter packed with an organic/inorganic, hybrid packing material made of clay pellets plus clay pellets covered by a thin layer of compost and inoculated with activated sludge from a municipal WWTP. Operating conditions under high loads of toluene were selected to force plant failure by clogging. The biofilter achieved a remarkably maximum elimination capacity of $595 \mathrm{~g}$ toluene $\cdot \mathrm{m}^{-3} \cdot \mathrm{h}^{-1}(1280 \mathrm{~g}$ toluene $\cdot \mathrm{m}^{-3} \cdot \mathrm{h}^{-1}$ based on the first $25 \mathrm{~cm}$ of the biofilter). The evolution of biofilter performance and biomass growth over the packing material were studied until the reactor collapsed. Several variables related to biomass growth such as reactor weight, oxygen consumption, $\mathrm{CO}_{2}$ production, substrate removal and pressure drop were monitored. Alternated periods of substrate supply and starvation were tested to assess biomass growth and detachment. Moreover, $\mathrm{pH}$ and biomass content were periodically measured in the leachate to determine the washing efficiency of intermittent watering. Pressure drop measurements demonstrated that watering was an effective technique to wash the excess of biomass accumulated. Experimental data also permitted to determine important parameters for biofilter modeling as the biomass growth yield and the stoichometric coefficients of toluene biological oxidation. Variables monitored are sensitive to biomass accumulation
\end{abstract}


and provided enough description of the system towards development of a comprehensive model considering biomass growth to predict and prevent clogging in equivalent processes.

KEYWORDS: biofilter clogging, toluene abatement, hybrid packing material, high load.

\section{INTRODUCTION}

Biofiltration of volatile organic compounds (VOC) employs the metabolic activity of microorganisms immobilized on a packing material to degrade gas phase pollutants which are the carbon and energy source for microbial growth. However, biomass accumulation is one of the most critical processes that need to be controlled along the operation of biofilters and biotrickling filters to achieve a stable performance during longterm operation. The excess of biomass inside the bioreactor significantly increases pressure drop, which ultimately may lead to external wash out of part of the biomass from the system or to force the replacement of the support media. Additionally, the excess of biomass leads to increased pressure drop that implies an increased operating cost. In addition, reduced removal efficiencies due to reduced specific surface areas and porosities are encountered. Channeling because of non-uniform biomass growth might also occur [1].

Organic volatile compounds, as toluene, are industrial chemicals produced widely in the world. The high interest of improving the knowledge of abatement techniques for VOCs are closely related to odor emissions as well as to the serious adverse human health effects recently reported. Even at low concentrations, toluene has been found to be carcinogenic, causes damage to the liver and kidney, paralyzes the central nervous system and causes genetic damage $[2,3]$. In particular, toluene has been widely studied as a model compound in biofiltration. Several authors have focused on toluene abatement by biofiltration at high loads (superior to $50 \mathrm{~g} \mathrm{~m}^{-3} \mathrm{~h}^{-1}$ ). Maximum elimination capacities reported while treating high toluene loads range from 50 to $240 \mathrm{~g} \cdot \mathrm{m}^{-3} \cdot \mathrm{h}^{-1}[4,5]$. Such large range depends on diverse factors such as the gas contact time, the type of packing material (organic or inorganic) or the growth of bacteria or fungi from enriched cultures as well as mixed cultures inocula. Exceptionally, Ryu et al. [6] reported a toluene elimination capacity of 3.7 $\mathrm{Kg} \cdot \mathrm{m}^{-3} \cdot \mathrm{h}^{-1}$ for a biofilter inoculated with a pure species (Stenotrophomonas maltophilia) 
using toluene as sole carbon and energy source. In addition, polyurethane foam as packing material showed able to overcome clogging problems by excessive biomass growth.

Several packing materials, both organic and inorganic, have been tested in biofiltration as support media for biomass immobilization. While organic materials are shown to be low-priced and suitable to potentially release inorganic nutrients and keep the water content at optimal levels for microorganisms, inorganic materials generally offer higher contact surfaces and durability [7]. Some tested hybrid materials for air pollutants removal by biofiltration have shown faster startups and more stable nitrification capacities than organic packings [8] as well as low pressure drop, acidification and compaction along biofilter operation [9].

Still, removal of high loads of toluene entails important operational difficulties. Several authors have reported that high inlet concentrations of toluene may reach toxic levels for the active micro flora, i.e. the biodegradation rate may be substrate inhibited $[4,10]$, thus having a reverse effect on the biodegradation reaction. In addition, excessive biomass growth occurs at high loads which may lead to biofilter malfunctioning. Alonso et al. [11] concluded that the excessive accumulation of biomass in a reactor has a negative effect on contaminant removal efficiency. However, mechanisms and dynamics of biomass accumulation are not well-understood or assessed in common biofiltration studies. The most common parameter measured to follow biomass accumulation is pressure drop due to its simplicity and immediacy requiring a minimum instrumentation. However, accuracy of this direct measure is low to obtain a good correlation with biomass since other effects can be hidden, as water accumulation by irrigation or channeling [1]. Moreover, substantial changes detected in pressure drop provide delayed information to adjust operation and avoid a clogging episode. Alternatively, monitoring biomass accumulation by determining the active and inert biomass fractions by means of counting cell numbers or protein assays $[12,13]$ are tortuous tasks and very sensible to the distribution and heterogeneity of biomass. Complementary, carbon dioxide production, as a result of oxidation of organic compounds by microorganism activity has been used satisfactorily in several studies $[14,15]$ to assess biomass excess and attend stable long-term performance. Therefore, 
simultaneous measurement of several parameters could be a complete and real solution to monitor biomass accumulation and to evaluate which conditions affect microorganisms activity and growth.

In the present work, the performance of a lab-scale biofilter treating high loads of toluene was assessed through extensive biofilter monitoring to quantify and understand biomass accumulation towards future modeling of the system. Parameters were monitored along the evolution of the biofilter from the inoculation to a forced clogging episode in five sampling ports along the height of the biofilter to determine the corresponding profiles during several periods of operation. Biomass detachment under starvation conditions and recovering from a long shutdown of the inlet load were also studied.

\section{MATERIALS AND METHODS}

\subsection{Experimental set-up}

Experiments were carried out in a lab-scale plant consisting of a PVC column with an inner diameter of $14.5 \mathrm{~cm}$ and a packing height of $1 \mathrm{~m}$ (Figure 1) with a total packing volume of $16.5 \mathrm{~L}$ and a bed porosity of 0.38 . Compressed air was passed through a water column in order to increase the relative humidity up to $80 \%$. The inlet air pressure and the gas flow rate were controlled and measured by means of a pressure regulator (Norgren Excelon, UK) and a mass flow controller (Bronhorst F-201CV, Germany), respectively. The gas flow rate was adjusted to $28 \mathrm{~L} \mathrm{~min}^{-1}$, corresponding to an empty bed residence time value (EBRT) of 35 seconds. Water was sprinkled by a high performance hollow-cone nozzle (Bete WL1, USA) located at the top of the fixed bed and by means of a peristaltic pump (Magdos LT-10, USA) in down-flow mode. The inlet pollutant concentration was achieved dispensing toluene (Panreac 99.5\%, Spain) by means of an automatic microburette (Crison 2S-D, Spain).

The reactor was packed with a mixture of a hybrid material based on clay pellets with a thin layer of compost and clays pellets without compost in a 1:4 ratio. The particle 
size of the packing material was 4-5mm. Physico-chemical characteristics of the packing material are described in a previous work (16), being referenced as "advanced material". The reactor was inoculated with $5 \mathrm{~L}$ of activated sludge from an urban WWTP located in Manresa, Spain, containing a total suspended solids (TSS) concentration of $1 \mathrm{~g} \mathrm{l}^{-1}$. The inoculation was performed by recirculating the inoculum for $24 \mathrm{~h}$. Afterwards, the lack of turbidity in the leachate collected at the bottom of the biofilter indicated that almost all biomass had been satisfactory attached to the support.

\subsection{Biofilter monitoring}

Gas-phase parameters were monitored through 5 sampling ports along the height of the biofilter in order to obtain properties profiles during operation. Sampling ports were tagged A, B, C, D and E, from biofilter inlet to outlet separated by a distance of $25 \mathrm{~cm}$. The biofilter performance was evaluated in terms of elimination capacity $(\mathrm{EC})$ ( $\mathrm{g}$ toluene. $\mathrm{m}^{-3}$ reactor $\cdot \mathrm{h}^{-1}$ ), which was calculated from the top of the biofilter to each sampling port (first quarter, from $\mathrm{A}$ to $\mathrm{B}$; half, from $\mathrm{A}$ to $\mathrm{C}$; three quarters, from $\mathrm{A}$ to $\mathrm{D}$; and the whole biofilter, from $\mathrm{A}$ to $\mathrm{E}$ ). Parameters monitored were toluene abatement, carbon dioxide production, oxygen consumption, pressure drop, temperature and humidity. Moreover, the biofilter was suspended from a weighting platform (Mettler Toledo X32001L, Spain) to continuously monitor its weight increase due to biomass growth. Additionally, room temperature was measured by means of a Pt-100-4 (Wika, Spain) to ensure a quasiisotherm operation $\left(23 \pm 2^{\circ} \mathrm{C}\right)$ through a controlled heating system.

Toluene concentration in air was measured from the sampling ports by an on-line photoionization detector (PID) (Photovac 2020, USA). The detector was connected to a computer via a RS232 port for continuous data collection. However, between day 17 and 55 gas samples were collected in Tedlar® bags due to the PID malfunctioning. In this case, toluene concentrations were measured in triplicate in each port using a gas chromatograph (Perkin Elmer Clarus 400, USA) equipped with a capillary column (N65110C0, Perkin Elmer, USA) and a flame ionization detector. Carbon dioxide and oxygen concentrations were measured on-line with a gas analyzer (Maihak S710, Germany) by infrared (IR) with 
a NDIR UNOR module for $\mathrm{CO}_{2}$ measurements and by paramagnetism with an OXOR-P module for $\mathrm{O}_{2}$ measurements. Pressure drop was determined by means of a differential pressure transmitter (Testo 6342, Spain) equipped with 4-20 mA output signal. Temperature and humidity were measured by an industrial transmitter (Hygrotest $650 \mathrm{HP}$, Spain).

A set of solenoid valves allowed for on-line monitoring of toluene concentration, carbon dioxide, oxygen consumption, differential pressure, temperature and humidity at the five sampling points. Analogical inputs and digital outputs were connected to a PCI-1711 data acquisition card (Advantech, Taiwan). A Supervisory Control and Data Acquisition (SCADA) system developed in LabWindows/CVI (National Instruments, USA) was used to automate and monitoring the pilot plant. The solenoid valves were programmed by means of the SCADA system to switch periodically the 5 sampling ports. Each solenoid valve was connected through PU tubing to the photoionization detector, the oxygen and carbon dioxide analyzer, the differential pressure transmitter and the temperature and humidity transmitter. Time programming of solenoid valves ensured that the samples reached each instrument after a cleaning cycle with compressed air. Thus, a value for each parameter monitored was obtained per sampling port at a frequency of, at least, once per day. This SCADA system was also used for regulating the water addition in order to keep suitable moisture content, provide the necessary nutrients for the microorganisms and wash out dead cells and end-products of toluene degradation. Nutrient solution was automatically sprinkled over the biofilter bed at a flowrate of $1400 \mathrm{~mL} \mathrm{~d}^{-1}$ (700 mL each 12 hours) by means of a diaphragm dosing pump (Alldoss Primus 221, Germany). Watering rate was 700 $\mathrm{mL}$ each 12 hours until day 45 and $1000 \mathrm{~mL}$ each 72 hours subsequently. The nutrient solution was composed by $\mathrm{KH}_{2} \mathrm{PO}_{4}\left(1 \mathrm{~g} \mathrm{~L}^{-1}\right), \mathrm{K}_{2} \mathrm{HPO}_{4}\left(1 \mathrm{~g} \mathrm{~L}^{-1}\right), \mathrm{NH}_{4} \mathrm{Cl}\left(1 \mathrm{~g} \mathrm{~L}^{-1}\right), \mathrm{NaCl}(1 \mathrm{~g}$ $\left.\mathrm{L}^{-1}\right), \mathrm{MgSO}_{4}\left(0.2 \mathrm{~g} \mathrm{~L}^{-1}\right), \mathrm{CaCl}_{2}\left(0.02 \mathrm{~g} \mathrm{~L}^{-1}\right)$ and trace elements $\left(1 \mathrm{~mL} \mathrm{~L}^{-1}\right)$. The excess of solution (leachate) was manually collected on a daily basis at the bottom section of the biofilter. Leacheate pH (Crison, Spain), TSS by Standard Methods (APHA, 1995) and total nitrogen content (Hach Lange LCK238, UK) were determined. Specific surface area of material $\left(76.8 \mathrm{~m}^{2} \mathrm{~g}^{-1}\right)$ was determined by the Brunauer-Emmett-Teller (BET) technique in a Micromeritics, model Tristar 3000, apparatus. The biofilm density was calculated by 
direct measurement of volume and weight of the immobilized biomass extracting part of the packing material at frequent operation times and scraping biomass from the surface.

\subsection{Experimental periods}

Biofilter performance was monitored for 120 days in 4 specific operating periods (Table 1) in which different pollutant loads where supplied. First, a short period of 4 days was considered as representative of the startup of the reactor. Secondly, the load was increased by a factor of 3 from day 4 on to force the system to accumulate biomass. A starvation period of 20 days without toluene feeding was established on day 55 of operation to assess the biomass decay rate. During the starvation period, the gas flow rate, the water supply as well as monitoring of the system were maintained. Later on, toluene supply was resumed and reactor performance was monitored until the end of the experimental period. The performance of the biofilter was assessed in terms of the elimination capacity (EC) and removal efficiency (RE) throughout all periods. It is worth mentioning that on day 18 a flooding episode occurred due to low initial bed porosity (0.38) and the high watering flowrate $\left(1400 \mathrm{~mL} \cdot \mathrm{d}^{-1}\right)$. The reactor was briefly stopped, drained and the operation was resumed. Finally, from day 90 to 95, a short, six-days feed supply failure occurred but normal operation was quickly recovered.

\section{RESULTS}

\subsection{Biofilter performance during toluene feeding periods}

A quick start-up period was observed in the biofilter. The RE quickly increased to around $96 \%$ after 72 hours of operation, which corresponded to outlet toluene concentrations below $15 \mathrm{ppm}_{\mathrm{v}}$ (Figure 2a). Profiles of $\mathrm{CO}_{2}$ measured during startup (Figure b) indicated that toluene was being biodegraded from the very beginning. When the inlet load was later increased up to $600 \mathrm{~g} \cdot \mathrm{m}^{-3} \cdot \mathrm{h}^{-1}$, a toluene breakthrough was observed until the

flooding episode on day 18. Interestingly, toluene concentration in sampling port E (outlet) was generally higher than concentration in sampling port D until the flooding episode, 
which indicates that some channeling occurred inside the biofilter due to uneven watering and biomass growth on the support material. During the flooding episode, the packing material was stirred and then channeling was lessened. The inversion of concentration in the latter sampling ports disappeared later on. The RE of the biofilter was almost 100\% along the whole period. Pollutant influent concentration fluctuated around $20 \%$ until the end of the pseudo steady-state period. These fluctuations in the inlet were consequence of the experimental setup due to pressure fluctuations in the line and to the liquid toluene injection system (small volume was required every long time for these conditions). A progressive increase in the toluene concentration was observed in all modules along time except for the first module, starting on day 20 in section C, on day 26 in section $\mathrm{D}$ and on day 38 on section E. Concomitantly, a reduced $\mathrm{CO}_{2}$ production was observed in all modules (Figure 2b). During the resumption period, from day 75 on, the biofilter was progressively fed with toluene until an inlet load of $390 \mathrm{~g} \cdot \mathrm{m}^{-3} \cdot \mathrm{h}^{-1}$ was reached. A rapid recovery of the RE after the long starvation period was encountered. RE was once again close to $99 \%$ a few hours after resumption, confirming that biomass was not completely inactive. From day 90 to 95 a feed failure was registered but the operation was rapidly recovered. Thus, the biofilter was able to cope with intermittent loads without being substantially affected.

Pressure drop measurements (Figure 3a) correlated well with the situations in which a clear decrease in the treatment capacity occurred, i.e. from day 39 to 55 and more slightly from day 98 to 120. In all cases, the pressure drop increased as a consequence of water and biomass accumulation in the bed probably leading to dead zones proliferation inside the reactor. Both water and biomass accumulations were linked to the rapid increase in biomass growth due to the high load of pollutant removed. On day 55, pressure drop across the biofilter was close to $40 \mathrm{~cm} \mathrm{wc} \cdot \mathrm{m}^{-1}$ and water trickling was almost impossible. Then, pollutant feed was interrupted while watering and leachate collection were kept. A similar situation occurred towards the end of the experimental period (day 110). Thus, the decrease in the bed porosity due to biomass growth increases the amount of water retained inside the biofilter which, in turn, increases the pressure drop through the packed bed. Interestingly, pressure drop measurements also correlated well with the mass of detached biomass 
measured as TSS in the leachate (Figure 3b), in particular during the periods towards the end of the steady and the resumption stages. In these cases, a large pressure drop increase in all modules led to an almost equivalent increase in the amount of biomass detached in the reactor. The increased detached biomass is also favored by the fact that mobile air velocity increased due to the lower porosity by accumulation of biomass by forcing the same air flow rate through the filter.

From day 45, the measured pressure drop reached a value over $100 \mathrm{~mm}$ WC indicating that a high biomass and water accumulation was occurring. To avoid water trickling problems, as the water mass balance and the analysis of nutrients measured in the leachate evidenced that moisture and nutrients were not limiting, the amount and frequency of irrigation was decreased from $700 \mathrm{~mL}$ each 12 hours to $1000 \mathrm{~mL}$ each 72 hour. Previous experiments (data not shown) under these watering conditions had shown positive performance. A previous flooding episode occurred on day 18 but this was not only consequence of a high watering rate. A failure of the automatic control system caused this flooding, which was satisfactory solved.

The overall performance of the biofilter in terms of toluene removal is shown in Figure 4, in which the EC is plotted versus the organic load in the different modules of the biofilter. Maximum ECs were found in the first and second modules, while the other two modules were generally close to $100 \% \mathrm{RE}$ because of the treatment of reduced loads. Maximum EC encountered were in the range of 1000 to $1280 \mathrm{~g} \cdot \mathrm{m}^{-3} \cdot \mathrm{h}^{-1}$ in the lower section of the bioreactor. Taking the whole reactor length into account, the average maximum EC encountered was $595 \mathrm{~g} \cdot \mathrm{m}^{-3} \cdot \mathrm{h}^{-1}$. Both ECs are significantly higher than previously reported ECs. In general, large ECs reported in the literature for toluene degrading biofilters are often encountered when fungi are the predominant microorganisms in the reactor [17]. During the steady operation period and the resumption periods, $\mathrm{pH}$ decreased down to values below 3 (Figure 5) suggesting that the initial bacterial population of the inoculum was replaced by fungal populations along the operation time [18]. It is hypothesized that the $\mathrm{pH}$ decrease was due to the production of acidic by-products such as benzoic acid, which arise from toluene degradation [19]. Throughout the experimental period with 
toluene feeding, an average production of $1290 \mathrm{~g} \cdot \mathrm{m}^{-3} \cdot \mathrm{h}^{-1}$ of $\mathrm{CO}_{2}$ was found. Similarly, oxygen consumption in this period was around $1130 \mathrm{~g} \cdot \mathrm{m}^{-3} \cdot \mathrm{h}^{-1}$ (Supporting Information, Figure S1). It is important to underline that both parameters, directly related with the biomass activity, were highly sensitive to changes in inlet conditions. Evolution of $\mathrm{CO}_{2}$ (Figure 2b) and $\mathrm{O}_{2}$ (Supporting Information, Figure S1) confirmed that the first and second modules were the most active of the whole biofilter.

\subsection{Starvation period in the biofilter}

Biofilter activity during starvation periods depends on several factors such as the type of packing material used, the amount of biomass accumulated and the operating conditions in terms of air, water and nutrients supply [20]. Although the pollutant inlet was stopped, carbon dioxide production kept a value of $70 \mathrm{~g} \cdot \mathrm{m}^{-3} \cdot \mathrm{h}^{-1}$ in the starvation period (Figure 2b), which indicates that the biomass was not completely inactive after 20 days of starvation. It is supposed that the organic matter of the packing material, the products of biomass lysis, the exopolysaccharide (EPS) of biofilm, and the by-products of toluene degradation were enough to maintain biomass active under endogenous conditions. Oxygen consumption (Supporting Information, Figure S1) correlated well with $\mathrm{CO}_{2}$ production. Regarding to the leachate $\mathrm{pH}$ (Figure 5), neutrality was recovered immediately by the effect of irrigation and the reduced biological activity due to the lack of substrate. Biomass detachment (Figure 3b) from the packing material increased notably during the starvation period, which is consistent with EPS usage, biomass lysis and the decrease in the pressure drop (down to $5 \mathrm{cmH}_{2} \mathrm{O} \cdot \mathrm{m}^{-1}$ ). Total nitrogen content of the leachate was used to estimate the amount of biomass detached, based on a standard elementary composition $\left(\mathrm{C}_{5} \mathrm{H}_{7} \mathrm{O}_{2} \mathrm{~N}\right)$ [21], which showed similar profiles to these found by TSS (Supporting Information, Figure S2). Data should permit to estimate a detachment rate for future modeling purposes contemplating biomass growth. The higher values of mass detected by TSS indicates that, apart from biomass, some parts of the support were present in the leachate, probably detached clay or compost from the hybrid packing material by the friction effect of watering and partial decomposition of the material. The rapid pressure drop decrease during the starvation period demonstrates that watering was an effective technique to wash the 
excess of biomass accumulated in the biofilter packed with the hybrid packing material. Similar results have been found by other authors [22,23] with other packing materials (mixture of matured compost and an organic binder, coconut fiber, digested sludge compost, peat and pine leaves, amongst others support media tested).

\subsection{Biomass production}

Experimental data permitted to evaluate the fraction of pollutant used to produce biomass. Toluene abatement in a biofilter is a biochemical reaction catalyzed by microorganisms. In the case of complete oxidation of toluene to carbon dioxide and water, $3.35 \mathrm{~g}$ of $\mathrm{CO}_{2}$ are produced per $\mathrm{g}$ of toluene consumed according to the oxidation reaction stoichiometry (Eq.1).

$\mathrm{C}_{7} \mathrm{H}_{8}+9 \mathrm{O}_{2} \rightarrow 7 \mathrm{CO}_{2}+4 \mathrm{H}_{2} \mathrm{O}$

Figure 6 shows a satisfactory correlation between the $\mathrm{CO}_{2}$ production and the toluene EC. In addition, the large load of toluene degraded lead to a $\mathrm{CO}_{2}$ production (superior to $2500 \mathrm{~g} \cdot \mathrm{m}^{-3} \cdot \mathrm{h}^{-1}$ ) higher than reported in previous works of toluene biodegradation by biofiltration, which ensures a reliable yield estimation. Stoichiometric coefficients can be obtained from the slope of the linear regression $\left(1.77 \mathrm{~g} \mathrm{CO}_{2}\right.$ produced $\mathrm{g}^{-1}$ toluene degraded). The difference between the experimental $\mathrm{CO}_{2}$ production ratio and that obtained with Eq.1 can be explained by the use of the contaminant as carbon source for microbial growth. According to the experimental results, the oxidation of toluene in the presence of a nitrogen source (ammonia or ammonium in aqueous phase at acid $\mathrm{pH}$ ), lead to the stoichiometry in the production of biomass (assuming a general composition) shown in Eq. 2.

$$
1.52 \mathrm{C}_{7} \mathrm{H}_{8}+8.66 \mathrm{O}_{2}+\mathrm{NH}_{3} \rightarrow \mathrm{C}_{5} \mathrm{H}_{7} \mathrm{O}_{2} \mathrm{~N}+5.62 \mathrm{CO}_{2}+4.07 \mathrm{H}_{2} \mathrm{O}
$$

Present results show that $53 \%$ of degraded toluene is effectively oxidized to $\mathrm{CO}_{2}$ and water; the remaining $47 \%$ fraction of the consumed toluene is used to produce

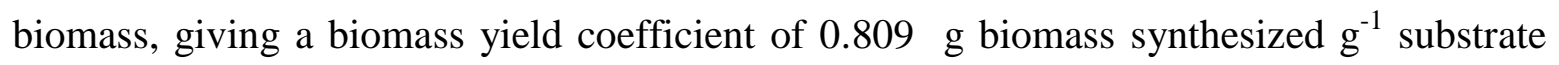


consumed. The evolution of biofilter weight in the operational period is shown in the Supporting Information file (Figure S3).

\section{DISCUSSION}

The use of packing materials combining the advantages of both organic and inorganic materials has been reported to improve the performance of biofilters, particularly in the case of the hybrid packing material studied herein. Hernández et al. [8] concluded that the clay particles covered by a thin layer of compost are a suitable support media for biofiltration of ammonia and several VOCs, providing fast, stable startups when selectively inoculated with enriched cultures. However, toluene was not one of the targeted VOCs. Morales et al. [24] also found a rapid start-up period (21 h) with a maximum toluene EC of $190 \mathrm{~g} \cdot \mathrm{m}^{-3} \cdot \mathrm{h}^{-1}$ in a biofilter inoculated with a consortium adapted to degrade toluene. However, this maximum EC was followed by a sharp decline until a stationary period with an EC of $8 \mathrm{~g} \cdot \mathrm{m}^{-3} \cdot \mathrm{h}^{-1}$. Similar to the present work, Ryu et al. [6] obtained a RE of $99 \%$ in 3 days in a biofilter inoculated with a pre-adapted inoculum using toluene as sole carbon and energy source. A fast start-up was found in the present study even though non-enriched cultures were used. Such fast start-up was attributed to the inoculum source as well as the sorption capacity of the packing material. According to Escalas et al. [25], toluene is the second most abundant VOC reaching the activated sludge process at the Manresa WWTP, in which large amounts of petroleum solvents were found. Thus, the inoculum is probably acclimated to abate organic compounds and may rapidly adapt to toluene in the biofilter. In addition, the fast start-up could be explained by a positive effect of a slight sorption capacity showed by the material, which was found to be between 0.02 and $0.04 \mathrm{mg} \cdot \mathrm{g}^{-1}$ depending on the water content of the bed [26]. In addition, the sorption capacity of the packing material permitted to reduce stress on the microbial population.

In addition to a fast start up of the bioreactor, a large, stable EC is desired. Only one previous work achieving an EC of the same order of magnitude has been found in the literature [6]. In that work, the biofilter was packed with polyurethane foam (PUF) with a specific surface area of $76.8 \mathrm{~m}^{2} \cdot \mathrm{g}^{-1}$. A large surface area such as that of PUF is generally 
linked to an improved gas-liquid mass transfer. Thus, larger ECs are expected whereas mass transfer limitations are minimized. It has been previously reported that biofilters packed with clay particles present a low mass transfer resistance at low empty bed residence time [27]. Comparing the EC achieved by the PUF biofilter normalized by the specific surface area, Ryu et al. [6] obtained an EC of $48.2\left(\mathrm{~g}\right.$ toluene $\left.\cdot \mathrm{m}^{-3} \cdot \mathrm{h}^{-1}\right) \cdot\left(\mathrm{m}^{2} \cdot \mathrm{g}^{-}\right.$ ${ }^{1}$ packing material $)^{-1}$ which is notoriously lower than $1684\left(\mathrm{~g}\right.$ toluene $\left.\cdot \mathrm{m}^{-3} \cdot \mathrm{h}^{-1}\right) \cdot\left(\mathrm{m}^{2} \cdot \mathrm{g}^{-}\right.$ ${ }^{1}$ packing material $)^{-1}$ obtained by the clay pellets covered with compost. Although the previous work was inoculated with a pure culture of Stenotrophomonas maltophilia T3-c, the elimination capacity of the mixed culture developed in the hybrid material was higher per square meter of material. However, although other factors influence the comparison as pressure drop and volume, present results show that microorganisms activity was favored by the characteristics of the hybrid material under the above conditions. Additionally, some authors indicate that at loads higher than $1000 \mathrm{~g} \cdot \mathrm{m}^{-3} \mathrm{~h}^{-1}$ toluene becomes inhibitory for bacterial activity and the EC drops down [5]. However, inlet loads above $1000 \mathrm{~g}$ toluene. $\mathrm{m}^{-3} \mathrm{~h}^{-1}$ were successfully removed by the non-specific consortium of the present study, which can be explained by the development of a fungal population according to the $\mathrm{pH}$ profile in Figure 5. Thus, results demonstrate that fungal biofilters can cope with larger toluene loads compared to bacterial biofilters.

Long-term bioreactor stability is demonstrated if stable ECs are maintained in a large period of time without a decrease in bioreactor performance. In this sense, the high load fed to the bioreactor served also to assess its long-term stability in a shorter period of time. The loss of performance encountered on days 20, 26, 38 in modules C, D and E, respectively, indicated that reactor stability was starting to diminish. In addition, short-term stability is defined by the reactor capability to face transient load changes by smoothing inlet concentration fluctuations as those tested on days 20 and 95 as well as after the starvation period. Short-term stability was probably due to the large amount of biomass grown in the reactor, mostly in the lower modules of the biofilter, which served to smooth inlet concentration fluctuations such as that on day 20. Interestingly, toluene and $\mathrm{CO}_{2}$ profiles between days 20 and 21 indicate that the first module of the biofilter was biologically limited, rather than mass transfer limited, which was also observed most of the 
time during biofilter operation. On the contrary, in the subsequent modules, and particularly on module 2, biomass immobilized on the support was able to cope with the load increase between days 20 and 21, meaning that the degradation capacity was not the limiting process. Although at higher gas-phase concentrations the mass transferred to the biofilm is enhanced, biomass immobilized on the first quarter of the biofilter was not able to cope with this increase, unlike the rest of the modules. In this sense, carbon dioxide production for the first module was kept constant while in the other modules increased proportionally. Once the first module was working at the maximum biodegradation capacity of the biomass, the upper modules received higher loads of toluene during load changes which were able to be treated by the immobilized biomass located further from inlet. However, biological limitation detected in the first and second module permitted to keep an active biomass in the whole height of the biofilter.

In the long run, biomass accumulation is detrimental and leads to an excessive water hold-up and, concomitantly, to a not viable pressure drop across the bed. Independently of clogging prevention, biological treatment of such high loads of pollutant needs of methods for facing clogging problems such as bed stirring, bed washing or nutrients control which permit removal of part of the excess biofilm without affecting the performance [23]. In addition, starvation, watering and air velocity resulted in an effective technique to wash the excess of biomass inside the biofilter packed with the hybrid packing, decreasing the pressure drop from 40 to $5 \mathrm{~cm} \mathrm{wc} \cdot \mathrm{m}^{-1}$. Then, enormous benefits in terms of biomass clogging prevention can be obtained if biomass growth can be estimated from simple measurements such a pressure drop. To this aim, developing a mathematical model able to predict biomass accumulation is a potential tool to improve biofilter performance and to operate under optimal conditions avoiding clogging episodes and their negative consequences. Experimental data collected during biofilter operation permitted to observe significant variations in the main parameters related to biomass accumulation which should allow to model biomass growth in the biofilter. In this sense, a proper estimation of the biomass growth yield is warranted. The biomass growth yield obtained in the present study is very similar to previous works in VOCs biofiltration. For instance, Alonso et al. [11]

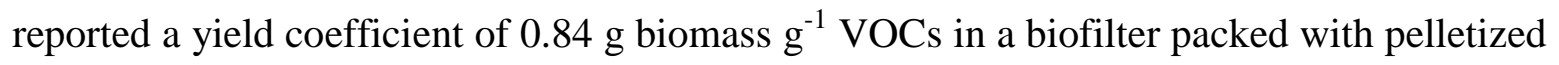


diatomaceous earth treating toluene. Comparatively, Delhoménie et al. [28] reported higher $\mathrm{CO}_{2}$ production (2.3 $\mathrm{g} \mathrm{CO}_{2} \cdot \mathrm{g}^{-1}$ toluene) in a biofilter packed with compost, meaning an effective conversion to mineral compounds of 69\%. Similarly, Alvarez-Hornos et al. [12] reported a conversion of $74 \%$ in the oxidation of toluene to $\mathrm{CO}_{2}$ on a peat-based biofilter. However, in both cases lower inlet loads of toluene were treated, 140 and $180 \mathrm{~g}$ toluene $\cdot \mathrm{m}^{-3} \cdot \mathrm{h}^{-1}$ respectively, which may indicate that at higher pollutant loads, the biomass production is enhanced, at mineralization expenses.

\section{CONCLUSION}

Biomass accumulation in a biofilter was enhanced by the high load of toluene treated, the particle size of the material, and its spatial distribution in the bed in order to collect information towards a better understanding of biomass growth by mathematical modeling. Results demonstrate that high loads of toluene can be treated by a non-specific consortium in biofiltration (up to $1280 \mathrm{~g} \cdot \mathrm{m}^{-3} \cdot \mathrm{h}^{-1}$ in the first $25 \mathrm{~cm}$ of the biofilter). However, it is necessary a strategy to control excessive biomass accumulation avoiding reactor clogging to ensure long-term operation. Moreover, present results demonstrated that the biofilter is able to recover rapidly the activity after several weeks of starvation. Overall, the success in the operation of the biofilter studied herein is partially explained by the suitability of clay pellets covered with compost according to the physical and chemical characteristics of the material, especially due to a high water retentivity that ensures a proper water content to keep biomass active.

\section{ACKNOWLEDGEMENTS}

Antonio David Dorado received a pre-doctoral scholarship of the MEC (Ministerio de Educacion y Ciencia, Spain). Authors acknowledge the financial support provided by the “Comision Interministerial de Ciencia y Tecnologia' (CICYT) and the European Regional Development Fund (ERDF-EC), projects CTQ 2006-14997-C02-02 and CTQ 2009-14338C03-03. The Department of Chemical Engineering at UAB is a unit of Biochemical 
Engineering of the Xarxa de Referencia en Biotecnologia de Catalunya (XRB), Generalitat de Catalunya.

\section{REFERENCES}

[1] C. Kennes, M.C. Veiga, Bioreactors for waste gas treatment, Kluwer Academic Publishers, Dordrecht, The Netherlands, 2001.

[2] M. Murata, M. Tsujikawa, S. Kawanishi, Oxidative DNA damage by minor metabolites of toluene may lead to carcinogenesis and reproductive dysfunction, Biochem. Biophys. Res. Commun. 261 (1999) 478-483.

[3] A.M. Moro, N. Brucker, M. Charao, R. Bulcao, F. Freitas, M. Baierle, S. Nascimento, J. Valentini, C. Cassini, M. Salvador, R. Linden, F. Thiesen, A. Buffon, R. Moresco, S.C. Garcia, Evaluation of genotoxicity and oxidative damage in painters exposed to low levels of toluene, Mutat. Res. 746 (2012) 42-8.

[4] M.C. Delhomenie, L. Bibeau, M. Heitz, A study of the biofiltration of high-loads of toluene in air: Carbon and water balances, temperature changes and nitrogen effect, Can. J. Chem. Eng. 83 (2005) 153-160.

[5] M. Zilli, A. Del Borghi, A. Converti, Toluene vapour removal in a laboratory-scale biofilter, Appl. Microbiol. Biotechnol. 54 (2000) 248-254.

[6] H.W. Ryu, S.J. Kim, K.S. Cho, T.H. Lee, Toluene degradation in a polyurethane biofilter at high loading, Biotechnol. Bioprocess Eng. 13 (2008) 360-365.

[7] A.D. Dorado, F.J. Lafuente, D. Gabriel, X. Gamisans, The role of water in the performance of biofilters: parameterization of pressure drop and sorption capacities for common packing materials, J. Hazard. Mater. 180 (2010) 693-702.

[8] J. Hernández, O.J. Prado, M. Almarcha, J. Lafuente, D. Gabriel, Development and application of a hybrid inert/organic packing material for the biofiltration of composting off-gases mimics, J. Hazard. Mater. 178 (2010) 665-672.

[9] W. Dan, Q. Me, Z. Yazhi, S. Chen, Removal of p-xylene from an air stream in a hybrid biofilter, J. Hazard. Mater. 136 (2006) 288-295. 
[10] S. Krailas, Q.T. Pham, R. Amal, J.K. Jiang, M. Heitz, Effect of inlet mass loading, water and total bacteria count on methanol elimination using upward flow and downward flow biofilters, J. Chem. Technol. Biotechnol. 75 (2000) 299-305.

[11] C. Alonso, M.T. Suidan, G.A. Sorial, F.L. Smith, P. Biswas, P.J. Smith, R.C. Brenner, Gas treatment in trickle-bed biofilters: Biomass, how much is enough?, Biotechnol. Bioeng. 54 (1997) 583-594.

[12] F.J. Alvarez-Hornos, C. Gabaldon, V. Martinez-Soria, P. Marzal, J.M. Penya-roja, M. Izquierdo, Long-term performance of peat biofilters treating ethyl acetate, toluene, and its mixture in air, Biotechnol. Bioeng. 96 (2006) 651-660.

[13] J.W. Hwang, C.Y. Choi, S. Park, E.Y. Lee, Biodegradation of gaseous styrene by Brevibacillus sp. using a novel agitating biotrickling filter, Biotechnol. Lett. 30 (2008) 1207-1212.

[14] Z.L. Cai, D. Kim, G.A. Sorial, Removal of methyl isobutyl ketone from contaminated air by trickle-bed air biofilter, J. Environ. Eng.-Asce 131 (2005) 1322-1329.

[15] Y. Fang, R. Govind, $\mathrm{CO} 2$ response to doses of organic solvents biodegraded in a batch biofilter, Water. Air. Soil Pollut. 175 (2006) 33-48.

[16] A.D. Dorado, F.J. Lafuente, D. Gabriel, X. Gamisans, A comparative study based on physical characteristics of suitable packing materials in biofiltration, Environ. Eng. 31 (2010) 193-204.

[17] E. Estévez, M. C. Veiga, C. Kennes, Biofiltration of waste gases with the fungi Exophiala oligosperma and Paecilomyces variotii, Appl. Microbiol. Biotechnol. 67 (2005) $563-568$.

[18] A.D. Dorado, G. Baquerizo, J.P. Maestre, X. Gamisans, D. Gabriel, J. Lafuente, Modeling of a bacterial and fungal biofilter applied to toluene abatement: Kinetic parameters estimation and model validation, Chem. Eng. J. 140 (2008) 52-61.

[19] F.X. Prenafeta-Boldu, D.M.A.M. Luyk, J. Vervoort, J.A.M. de Bont, Fungal metabolism of toluene: monitoring of fluorinated analogs by F-19 nuclear magnetic resonance spectroscopy, Appl. Environ. Microb. 67 (2001) 1030-1034.

[20] J. S. Devinny, M.A. Deshusses, T.S. Webster, Biofiltration for air pollution control, Lewis publishers: Boca Raton, Florida, 1999. 
[21] WEF (Water Environmental Federation), Design of municipal wastewater treatment plants. Manual of Practice no.8. ASCE Manual and Report on Engineering Practice no.76. WEF, Alexandria, NY, 1992.

[22] J.P. Maestre, X. Gamisans, D. Gabriel, J. Lafuente, Fungal biofilters for toluene biofiltration: Evaluation of the performance with four packing materials under different operating conditions, Chemosphere 67 (2007) 684-692.

[23] M.C. Delhomenie, L. Bibeau, J. Gendron, R. Brzezinski, M. Heitz, A study of clogging in a biofilter treating toluene vapors, Chem. Eng. J. 94 (2003) 211-222.

[24] M. Morales, R. Auria, F. Perez, S. Revah, Start-up and ammonia additions to biofilter for removal toluene. Biotechnol. Bioeng. 60 (1998) 483-491.

[25] A. Escalas, J.M. Guadayol, M. Cortina, J. Rivera, J. Caixach. Time and space patterns of volatile organic compounds in a sewage treatment plant. Water Res. 37 (2003) 39133920.

[26] A.D. Dorado, F.J. Lafuente, D. Gabriel, X. Gamisans, A comparative study based on physical characteristics of suitable packing materials in biofiltration, Environ. Eng. 31 (2010) 193-204.

[27] A.D. Dorado, G. Rodriguez, G. Ribera, A. Bonsfills, D. Gabriel, J. Lafuente, X. Gamisans, Evaluation of mass transfer coefficients in biotrickling filters: Experimental determination and comparison to correlations. Chem. Eng. Technol. 32 (2009) 1941-1950. [28] M.C. Delhomenie, L. Bibeau, N. Bredin, S. Roy, S. Broussau, R. Brzezinski, J.L. Kugelmass, M. Heitz, Biofiltration of air contaminated with toluene on a compost-based bed, Advances in Environmental Research 6 (2002) 239-254. 


\section{TABLE CAPTIONS}

Table 1. Experimental conditions in the different studied periods. Average and standard deviations of concentrations and loads are shown.

\section{FIGURE CAPTIONS}

Figure 1. Schematic of the lab scale plant: 1: mass flow meter; 2: humidification column; 3: micro-burette; 4: nutrients tank; 5: peristaltic pump; 6: biofilter; 7: scales; 8: differential pressure meter; 9: VOC's detector; 10: $\mathrm{CO}_{2} / \mathrm{O}_{2}$ analyser; 11: computer; 12: data acquisition hardware and relays. A, B, C, D and E are the sampling ports located from the inlet to the outlet.

Figure 2. Evolution of a) toluene and b) $\mathrm{CO} 2$ concentrations in the operation of the biofilter at the reactor inlet (A), first module (B), second module (C), third module (D) and reactor outlet (E).

Figure 3. Evolution of a) differential pressure in the operation of the biofilter at the reactor inlet (A), first module (B), second module (C), third module (D) and reactor outlet (E) and b) cumulative mass of detached biomass in the leachate through TSS analysis.

Figure 4. Elimination capacity (EC) in front of volumetric pollutant load during the biofilter operation.

Figure 5. Evolution of $\mathrm{pH}$ of the leachate along the operation of the biofilter.

Figure 6. Carbon dioxide production in front of elimination capacity to evaluate biomass yield coefficient. 